\title{
Managing Prerequisites for Junior Course CMOS VLSI in Electronics Engineering
}

\author{
Sanjay $\mathbf{E}^{\mathbf{1}}$, Uma $\mathrm{M}^{2}$ \\ ${ }^{1}$ ECE Department, KLE Technological University, BVB Campus, Hubli, India \\ ${ }^{2}$ ECE Department, KLE Technological University, BVB Campus, Hubli, India \\ 1eligar@bvb.edu \\ 2uma@bvb.edu
}

\begin{abstract}
This paper proposes a method to: (i) identify the prerequisite concepts in a Junior course CMOS VLSI Circuits (ii) assess the competency of students in the identified concepts (iii) identify the weak concepts, and (iv) provide remedial measures for addressing the weak concepts. The study pertains to undergraduate students of Electronics and Communication Engineering. Prerequisites for a course are the required prior knowledge of concepts learnt in previous semesters. The student attainment in the course will be adversely affected, if the attainment in prerequisite courses is not satisfactory. The pedagogical practices of providing awareness of the extent of linkage to prerequisites for the course, and retention of concepts for future courses are also presented here. Engineering education is a phase wise advancement of the student from Freshman to Sophomore, Junior and Senior. At each level of education the student is faced with a daunting task of retaining the concepts learnt in previous semesters and applying these concepts to understand new concepts or solve engineering problems. An attainment of $66 \%$ in the relevant course outcomes in previous semester provides the basis for identification of weak concept, which is further tested for retention by conducting a quiz in the identified concept.
\end{abstract}

Keywords: prerequisites, prerequisite courses, course outcomes, curriculum structure, attainment

\footnotetext{
Sanjay $\mathbf{E}^{1}$

${ }^{1}$ ECE Department, KLE Technological University, BVB

Campus, Hubli, India

1'eligar@bvb.edu
}

\section{INTRODUCTION}

Prerequisites for a course are the required prior knowledge of concepts learnt in previous semesters. The courses where these concepts are learnt are called prerequisite courses. At the higher semester of Junior and Senior level, most of the courses require certain prerequisites to be retained from previous semesters.

The student attainment in a course will be adversely affected, if the attainment in prerequisite courses is not satisfactory. This is due to the fact that a strong competency in prerequisites is essential to grasp the advanced concepts in the new course, and also to apply the concepts to solve engineering problems. Electronics and Communication Engineering (ECE) Program covers a wide range of study which includes Electronic Devices and Circuits, Signals and Systems, Control Engineering, and emerging areas like VLSI, Digital Signal Processing and Embedded Systems. The student is more likely to be overwhelmed by the sheer breadth of various domains of ECE. The department-level courses are only offered from Sophomore-level, with the exception of a basic course at Freshman-level. The approximate breakup of courses at various levels is: Fundamental Courses at Sophomore-level, Applied courses at Junior-level, and Advanced Courses at Senior-level.

In most of the cases, the prerequisite courses are learnt in the preceding semester. In such cases the concepts are still fresh, and the student can easily apply them in the ongoing semester. Prerequisites pose a challenge to the student if the gap is more than a semester. The study presented here addresses the case where the prerequisite course is at III Semester (Sophomore), while the course under study is at V Semester (Junior). The entire paper addresses only at the course-level in the context of its prerequisites and courses in later semesters which need prerequisites from the course under study.

There are many aspects to the challenge of retention of concepts from prerequisite courses, some of which are listed in Table 1. 
TABLE 1. ISSUES IN PREREQUISITES

\begin{tabular}{|l|l|}
\hline$\#$ & Issues \\
\hline 1. & Identifying the prerequisites \\
\hline 2. & Assessing the competency in prerequisites \\
\hline 3. & Identifying the weak concept/s \\
\hline 4. & Providing remedial measures for the weak concept/s \\
\hline 5. & $\begin{array}{l}\text { Preparing students for prerequisites of next semesters } \\
\text { (Retention) }\end{array}$ \\
\hline
\end{tabular}

Literature in Engineering Education has addressed all the issues, and in particular issue 5 to a greater extent. In [1] the authors present a review of concept mapping applications in Electrical and Computer Engineering. The study presents how the students co-relate the courses, and accordingly apply the concepts in higher-level courses. The student prepares for the challenges ahead, by effectively learning the fundamental concepts.

In [2] a review of concept mapping applications in Electrical and Computer Engineering is presented along with a review of different learning styles, and different concept maps generating software. It presents an effective way to remember the concepts learnt in previous semesters.

In [3] the authors focus on the need to design curriculum that meets the ABET criteria, and issues in transforming from content driven curriculum to outcome driven curriculum. The disjointedness in a content driven curriculum is reflected in the blank stares of incomprehension familiar to all engineering faculty members who have ever asked their students about material from a prerequisite or co-requisite course.

In [4] the authors explores the problem of unreadiness and the effectiveness of taking time to strengthen students' prerequisite knowledge in a course using sophomore and junior mechanics classes. The paper recommends that in order to improve learning and teaching in mechanics, student preparation should begin long before a prerequisite test.

In [5] the authors address the issue of student retention related to not being effective in meeting the prerequisite standards in Calculus. The solution is to redesign the curriculum, so that Calculus could be pushed to higher semester, when the student is ready for the challenge.

In this paper we present the experience of addressing issues 1 to 4 listed in Table 1 for Junior students in the course "CMOS VLSI Circuits", of undergraduate course in "Electronics \& Communication Engineering" during the years 2013-17.

The entire process begins at the beginning of a semester and the time frame is around one week. The course instructor is faced with a challenge of

(i) identifying the prerequisites (offline)

(ii) assessing students' competency in prerequisites (1 hour)

(iii) identifying the weak concepts (offline)

(iv) providing remedial measures for addressing the weak concepts ( 3 hours)
The distribution of sections in the rest of the paper is: Section 2 presents the curriculum structure highlighting the prerequisite courses and provides the context for the course under study. Section 3 describes the process of identifying the prerequisite concepts in the course through listing of course content with relevant concepts. In Section 4 we present the strategy to assess the student competency in relevant prerequisite concepts and identifying the weak concept/s. Finally in Section 5 we demonstrate the method of addressing the weak concept/s.

\section{Prerequisite Courses in Curriculum}

The undergraduate course in Electronics and Communication Engineering consists of four years (Freshman, Sophomore, Junior and Senior) spread over eight semesters. The curriculum has courses spread over multiple domains of Basic Science, Math \& Engineering, Humanities, Foundation courses, Embedded, VLSI, Communication and Integrating experiences.

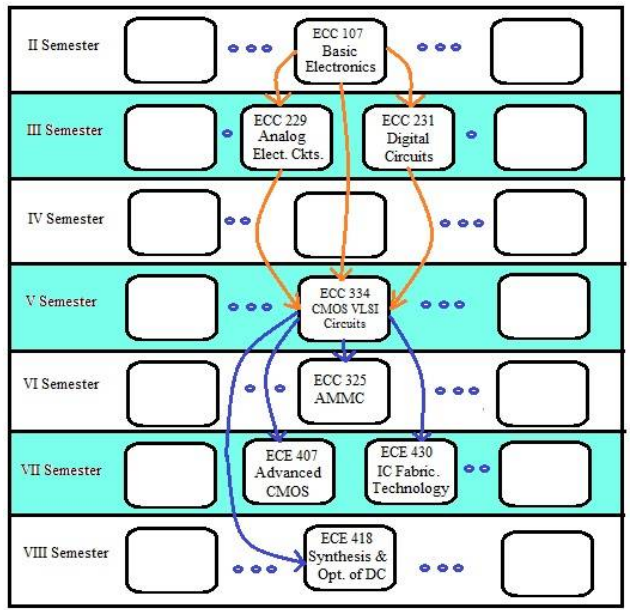

Fig. 1 Curriculum structure of ECE

Fig. 1 depicts the course CMOS VLSI Circuits (ECC334) along with its prerequisite map, and also the courses interlinked in next semesters. It is evident that the student is made aware of the interlinking of various courses. Table 2 lists the prerequisite courses at various semesters for the course.

\begin{tabular}{|lc|}
\multicolumn{2}{c}{ TABLE 2. PREREQuisite COURSES } \\
\begin{tabular}{|lc|}
\hline Course & Semester \\
\hline Basic Electronics (ECC 107) & II \\
\hline Analog Electronic Circuits (ECC 229) & III \\
\hline Digital Circuits (ECC 231) & III \\
\hline
\end{tabular}
\end{tabular}

The curriculum structure only indicates the connectivity between courses, but does not specifically depict the relevant concepts needed for future courses. These issues need to be addressed in the future curriculum design and development cycle. As seen from Table 2, there is a lot of time gap between the prerequisite courses and course offered in Semester V. This time gap could also possibly be the reason for failure to retain the concepts satisfactorily. The next section deals with identification of 
the prerequisite concepts as mapped to topic-wise content in the course.

\section{Identifying the Prerequisite Concepts}

The delivery strategy of the course starts with lesson plan document, which comprises of outcome based delivery and assessment, prerequisite concepts listing, chapter-wise plan and review questions. Table 3 lists the course outcomes, Table 4 lists the prerequisites and Table 5 provides the chapter-wise listing.

TABle 3. Course Outcomes

\begin{tabular}{|l|l|}
\hline$\#$ & Course Outcomes \\
\hline $\begin{array}{l}\text { At the end of the course the student should be able to: } \\
1 .\end{array}$ & $\begin{array}{l}\text { Model the DC Characteristics and delays of CMOS logic } \\
\text { circuits }\end{array}$ \\
\hline 2. & $\begin{array}{l}\text { Outline the CMOS IC fabrication process \& interpret layout } \\
\text { design rules }\end{array}$ \\
\hline 3. & $\begin{array}{l}\text { Design complex CMOS logic circuits using stick diagrams and } \\
\text { algorithms }\end{array}$ \\
\hline 4. & Design combinational and sequential CMOS logic structures \\
\hline 5. & Illustrate the CMOS VLSI design flow from logic to tapeout \\
\hline
\end{tabular}

TABle 4. Prerequisite CoNCEPTS

\begin{tabular}{|c|l|}
\hline Pre \# & Prerequisite Concepts \\
\hline 1. & $\begin{array}{l}\text { Basic operation of PN-junction } \\
\text { Design of Digital Logic gates \& Complex Logic Circuits } \\
\text { using Boolean algebra }\end{array}$ \\
\hline 3. & Device characteristics of MOSFET \\
\hline
\end{tabular}

TABle 5. Chapter-Wise Content

\begin{tabular}{|c|l|}
\hline Ch \# & Chapter Title \\
\hline 1. & Electronics Analysis of CMOS logic gates \\
\hline 2. & Basic CMOS Technology \\
\hline 3. & Designing High-Speed CMOS Logic Networks \\
\hline 4. & Combinational and Sequential CMOS Circuit Design \\
\hline 5. & VLSI Design Flow \\
\hline
\end{tabular}

The lesson plan document does not map the prerequisite concepts to the relevant chapters. So, as a first exercise we map the extent of application of the prerequisite concepts in the course, which is depicted in Table 6.

\begin{tabular}{|ccc|c|c|c}
\hline \multicolumn{7}{|c}{ TABLE 6. MAPPING OF PREREQUISITES TO CONTENT } \\
\hline Pre \# & $\begin{array}{c}\text { Prerequisite } \\
\text { Concept }\end{array}$ & $\begin{array}{c}\text { Prereq. } \\
\text { Course }\end{array}$ & $\begin{array}{c}\text { Ch } \\
\text { Con }\end{array}$ & Hours & Weight \\
\hline 1. & $\begin{array}{l}\text { Basic operation } \\
\text { of PN-junction }\end{array}$ & ECC 107 & 2 & 10 & $20 \%$ \\
\hline 2. & $\begin{array}{l}\text { Device } \\
\text { characteristics } \\
\text { of MOSFET }\end{array}$ & ECC 229 & 1 & 10 & $20 \%$ \\
\hline $\begin{array}{l}\text { Design of } \\
\text { Digital Logic } \\
\text { gates \& } \\
\text { Complex Logic } \\
\text { Circuits using } \\
\text { Boolean algebra }\end{array}$ & ECC 231 & 3,4 & 20 & $40 \%$ \\
\hline
\end{tabular}

The mapping methodology creates awareness in the student about the extent of application of relevant prerequisites in the course. The student will not be able to understand the new concepts, or apply the learnt concepts to effectively solve new problems in these chapters. As seen from Table 6 , almost $90 \%$ of the content is strongly related to the prerequisite concepts. It also depicts how strongly the Pre \# 3 is linked to the course (40\%). The student attainment in the course will be adversely affected, if the attainment in prerequisite courses is not satisfactory.

Once the prerequisite concepts are identified and mapped to the content, the next step is to assess the competency in these concepts and identify the weaker concept/s.

\section{Assessing the Competency in Prerequisite CONCEPTS AND IDENTIFYING THE WEAK CONCEPTS}

Before commencing the delivery of the content, we assess the competency in the prerequisites. This is essential to understand the advanced concepts as mentioned earlier. If the student is found short of the benchmark, then we identify and address these prerequisites before commencing the new course. This is also essential in keeping the students interested in the course.

\section{A. Interpreting Attainment Data}

The method involves collecting data from attainment of outcomes in prerequisite courses. The relevant course outcomes (COs) in the prerequisite courses are listed in Table 7. COs are framed in the prerequisite courses, and we map them to prerequisite concepts in the ongoing course. During mapping it is observed that prerequisites are often a subset of the relevant COs, but since we do not have a smaller resolution data, we interpret this data as reflecting the entire prerequisite concept. By this assumption we are adding a certain error in our assessment. As seen later we use this metric to only identify the weak concept, and our methodology is flawed only if the attainments of prerequisites are closely grouped.

\section{Table 7. Relevant COS in Prerequisite Courses}

\begin{tabular}{|l|c|l|}
\hline Course & CO \# & \multicolumn{1}{c|}{ CO } \\
\hline ECC 107 & 2 & $\begin{array}{l}\text { Analyze the characteristics of semiconductor } \\
\text { devices and their applications in rectifiers, } \\
\text { amplifiers and oscillators }\end{array}$ \\
\hline ECC 229 & 1 & $\begin{array}{l}\text { Explain the terminal behavior of the devices } \\
\text { such as junction Diode, BJT \& MOSFET and } \\
\text { identify the region of operation with its } \\
\text { equivalent circuit model }\end{array}$ \\
\hline ECC 231 & 2 & $\begin{array}{l}\text { Design combinational and sequential logic } \\
\text { circuits }\end{array}$ \\
\hline
\end{tabular}

The student attainment in prerequisite concepts for Semester End Examination (SEE) is listed in Table 8. The data is obtained from attainment in respective $\mathrm{COs}$ of prerequisite courses. Although we have not mapped the data from Continuous Internal Evaluation (CIE), the SEE data can be assumed to be strongly correlated to the CIE data.

TABLE 8. ATtAinment DATA FOR PREREQUisite CONCEPTS

\begin{tabular}{|c|c|c|c|c|}
\hline Pre \# & Course & SEE & Attainment & CO \# \\
\hline 1. & ECC 107 & June 2014 & $74 \%$ & 2 \\
\hline
\end{tabular}


TABLE 8. ATtAINMENT DATA FOR PREREQUisite CONCEPTS

\begin{tabular}{|c|c|c|c|c|}
\hline Pre \# & Course & SEE & Attainment & CO \# \\
\hline 2. & ECC 229 & January 2015 & $66 \%$ & 1 \\
\hline 3. & ECC 231 & January 2015 & $74 \%$ & 2 \\
\hline
\end{tabular}

$\%$ Attainment is defined as (Average / Max Marks) for each question by attempted students. The attainment data points to the strong and weak points in the concepts learnt. Accordingly Pre \#1 and Pre \#3 are satisfactorily attained (74\%), while Pre \#2 is a concern (64\%). The actual attainment which considers all the students is even lesser at $43 \%$. The actual attainment metric takes into account the average, irrespective of attempts made or otherwise. So, the data can be interpreted as: "most of the students have not attempted with conviction". Hence we identify "Device characteristics of MOSFET" which is Pre \#2 as a weak concept, and proceed further. The overall assessment outcome of prerequisite courses is shown in Fig. 2.

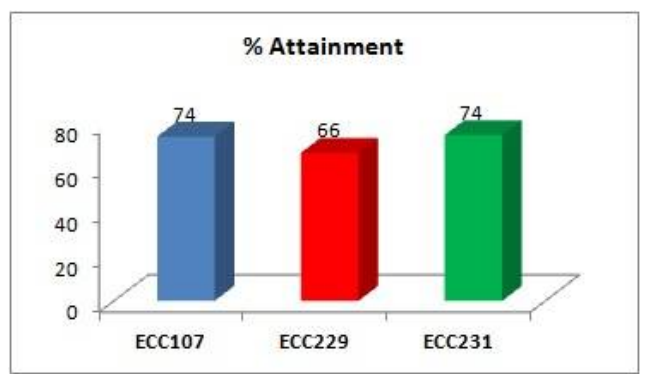

Fig. 2. Attainment percentage in prerequisite courses for relevant COs

After an informal interaction with the students, we convey Pre \#2 as a weak link, which needs remedial action.

\section{B. Assessing Retention of Weak Prerequisite Concept}

Assessing the student for retention of this weak concept is the next process. The prerequisite test provides insight into both the competency of the student in weak concepts as well as retention of the concepts. Students are asked to form teams of three members each based on their choice. The questions are carefully chosen to highlight the relevance of these concepts to the course. The teams are allowed to discuss (intra-team) and ponder over the possibly confusing answers. This allows the students to dig deeper into the concepts to find the right answers. The reason we choose to have a team-based assessment is that no student likes to face an exam immediately at the commencement of a new semester. So we need to make the process as a fun-learn activity, without explicitly conveying our intent of assessing the students. This approach not only ignites curiosity and interest among the students towards the course, but also allows a soft take-off for the course. The activity can be thought provoking only if the questions are intelligently posed to create ambiguity in the answers. Only if the relevant concepts are clear can the questions be answered satisfactorily. We still need to insert a few questions with obvious answers so that the interest is maintained throughout the duration of quiz paper.

The quiz questions are listed in Table 9. The questions listed here relate to the device operation of NMOS FET.
TABle 9. PRerequisite Quiz Questions

\begin{tabular}{|c|c|}
\hline$\#$ & Question \\
\hline 1. & Is it possible to obtain a large Id when $\mathrm{Vds}=0 ?$ \\
\hline 2. & What is the type of inversion layer? \\
\hline 3. & Is it possible to obtain a large Id when $\mathrm{Vgs}=\mathrm{Vt}$ ? \\
\hline 4. & $\begin{array}{l}\text { What effect does increasing Vgs have on the depth of the } \\
\text { inversion layer? }\end{array}$ \\
\hline 5. & Which end of inversion layer is deeper? \\
\hline 6. & $\begin{array}{l}\text { At saturation what is the voltage between the gate and drain } \\
\text { end of the channel? }\end{array}$ \\
\hline 7. & $\begin{array}{l}\text { What effect does increasing Vgs have on the resistance of the } \\
\text { channel? }\end{array}$ \\
\hline 8. & What effect does increasing Vgs have on the saturation Vds? \\
\hline 9. & What has most effect on Id in saturation region? \\
\hline 10. & $\begin{array}{l}\text { What effect does increasing Vds have on Id in the saturation } \\
\text { region? }\end{array}$ \\
\hline
\end{tabular}

The responses of the students are summarised in Fig. 3. A total of 62 students participated in the quiz spread over 22 teams comprising of $2 / 3$ students. The results can be interpreted as weak with regards to both understanding of the prerequisite concepts, and also to poor retention. The faculty now has to identify the strong and weak points in this domain and evolve ways of dealing effectively with the situation.

As seen from Fig. 3 the strong concepts are related to those above the average line, and we set this as a benchmark to determine the weaker concepts. Accordingly Q4 and Q8 are identified as the concepts which are either misinterpreted or difficult to retain. After interacting with students in the classroom, the cause for such a low response is found to be unclear interpretation of concepts in the previous course and also failure to retain because of time gap between relevant semesters. The questions relate to deeper analysis of $\mathrm{V}_{\mathrm{gs}}$ effect on MOSFET performance.

The course instructor often feels the reason for not retaining the concepts could be due to ineffective pedagogical practices in previous semesters, but the real reason could be the time gap across the semesters. In any case the course instructor has to precede any course by revisiting the prerequisite concepts in some detail.

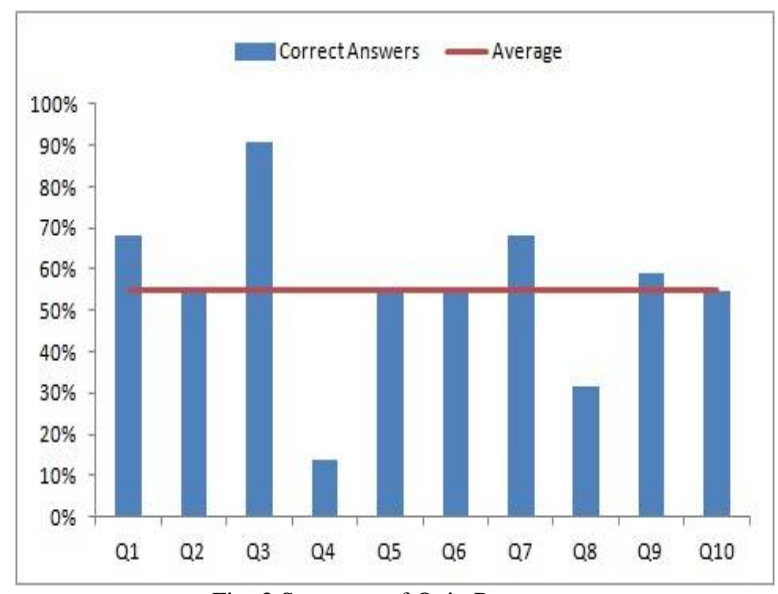

Fig. 3 Summary of Quiz Response 


\section{Providing Remedial Measures for Weak CONCEPTS}

The next step is to address the weak concepts in the ongoing semester. The remedial measures taken are briefly listed here.

\section{A. Using visual techniques to learn concepts}

Free online resources are used by the student, aided by the course instructor to study the behaviour of a N-channel MOSFET under different terminal voltages $\mathrm{V}_{\mathrm{gs}}$ and $\mathrm{V}_{\mathrm{ds}}$. It includes a flash video file which is interactive, allowing the user to choose answers and analyze the reasons for a particular behaviour. A snapshot of the tool is shown in Fig. 4. Students enthusiastically collaborated with each other in the learning process and even debated the ambiguous answers.

The prerequisite quiz questions are revisited by the students, to justify the appropriateness of the answers. The question with weakest response is $\mathrm{Q} 4$, which relates to the depth of inversion layer with increasing $\mathrm{V}_{\mathrm{gs}}$. The tool allows the user to apply various voltages from $0 \mathrm{~V}$ to $5 \mathrm{~V}$, and depict the depth of inversion layer for each of these cases through animation.
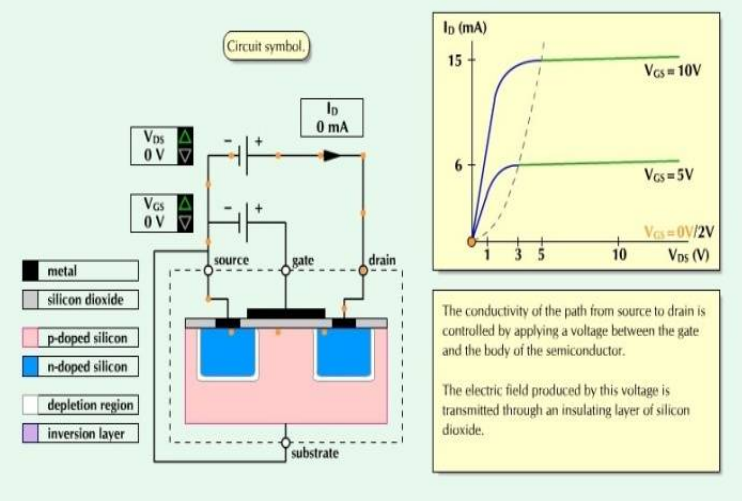

Fig. 4 Visual aid to learn MOSFET concepts

B. Sharing relevant course material on webpage

Apart from the visual content, additional course material in the form of power point presentations is uploaded to the course web page designed exclusively for the course. The snapshot of the course webpage is shown in Fig. 5. In many cases the course instructor may recommend revisiting the notes of previous semesters, but without any strategy for retention like concept maps, the student is often disinterested. The onus is now upon the course instructor to provide visually effective course material specifically addressing the weak concept. In the course we uploaded a power point presentation titled "prerequisites" on the course webpage, which contains detailed analysis of MOSFET device operation.

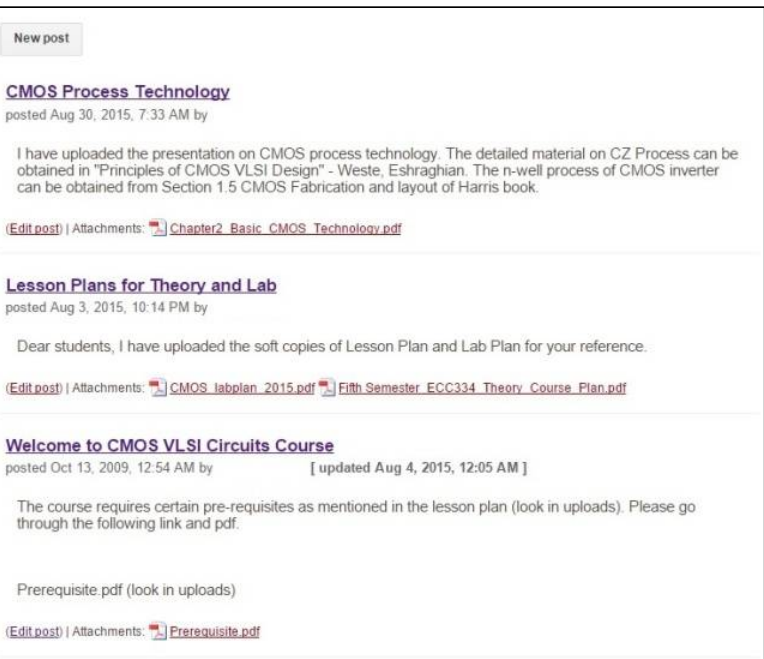

Fig. 5 Course web page sharing content on prerequisite concepts

C. Classroom teaching-learning activity

Follow-up classes are scheduled to further discuss the content uploaded. Here the course instructor collaborates with students in an active teaching-learning framework to fine tune the concepts.

\section{Lab based activity}

The course is also associated with a Laboratory Course "CMOS VLSI Circuits Lab". The lab provides an opportunity to explore the behaviour of MOS devices by using the simulation platform. The lab structure includes demo, exercise, structured-enquiry and open-ended experiments, to allow a 360 degree exposure to real world fabrication technology in UMC180 using Cadence EDA tool. This enhances the device-level competency.

The first exercise experiment is to study the behaviour of both NMOS and PMOS devices in UMC 180 technology. All the analysis of transient, dc and parametric are performed to understand the variation of $I_{d}$ with changes in $\mathrm{V}_{\mathrm{ds}}$ and $\mathrm{V}_{\mathrm{gs}}$. This strengthens the concepts learned in previous remedial activities.

E. Addressing retention of concepts in future courses

The experience of identifying the weak prerequisites and addressing the issues leads us to providing a framework for future courses where concepts from the ongoing course are applied. Table 10 lists the future courses along with their time of occurrence. The students need to apply the concepts learnt in this course in various integrating experiences like Mini-Projects, Minor-Projects and Capstone Projects, apart from various student competitions at University, National and International levels. Various methods of improving the retention of concepts are currently being explored.

TABLE 10. Future COURSES FOR RETENTION OF CONCEPTS

\begin{tabular}{l|c}
\hline Course & Semester \\
\hline Analog \& Mixed Mode Circuits (ECE325) & VI \\
\hline Advanced CMOS VLSI Circuits (ECE407) & VII \\
\hline
\end{tabular}




\begin{tabular}{|l|c|}
\hline Course & Semester \\
\hline IC fabrication Technology (ECE 430) & VII \\
\hline $\begin{array}{l}\text { Synthesis and Optimization of Digital Circuits } \\
\text { (ECE418) }\end{array}$ & VIII \\
\hline
\end{tabular}

At the end of these remedial measures, the students are confident enough to venture into the new course.

\section{COnClusion And Future Work}

This paper presented the issues in identifying the prerequisite concepts in a course at Junior level, and method to assess and identify the weak concepts. Pre \# 2 was chosen as a weak concept to be addressed since the SEE attainment was very low at $66 \%$. Various methods for identification of gaps and remedial measures were also presented. The strong linkage of prerequisites to the course is quantified, and awareness is also created for retention of concepts to be applied in future courses at higher semesters.

The future work is to devise a methodology for retention of concepts learnt in ongoing semester to prevent the repetition of issues experienced here.

\section{REFERENCES}

[1] Rasha, Wael Ibrahim and Frances Williams (2007) Concept maps: Development and validation of engineering curricula, Frontiers In Education Conference-Global Engineering: Knowledge Without Borders, Opportunities Without Passports, FIE'07. 37th Annual IEEE.

[2] Ibrahim, Wael, Rasha Morsi and Theresa Tuttle, (2006), Concept Maps: An active learning and assessment tool in Electrical and Computer Engineering, American Society for Engineering Education.

[3] Felder, Richard, M. and Rebecca Brent, (2003) Designing and teaching courses to satisfy the ABET engineering criteria, Journal of Engineering EducationWashington- 92.1 pp 7-26.

[4] Efimba, Robert, E. and Tori Rhoulac Smith. (2012), Prerequisite Courses and retentivity as a Challenge for Students in Engineering Mechanics, American Society for Engineering Education.

[5] Ohland, Matthew, W., Amy, G. Yuhasz, and Benjamin L. Sill. (2004), Identifying and removing a calculus prerequisite as a bottleneck in Clemson's General Engineering Curriculum, Journal of Engineering Education-Washington - 93, pp 253-258.

[6] Kinzie, J. (2012), Carnegie Mellon University: Fostering assessment for improvement and teaching excellence, Urbana, IL: University of Illinois and Indiana University, National Institute for Learning Outcomes Assessment.

[7] Weste, Neil, David Harris, and Ayan Banerjee (2006), CMOS VLSI Design: A circuits and systems perspective, 3rd Edition, Pearson Education.

[8] Uyemura, John P. (2002), Introduction to VLSI circuits and systems, 1st Edition, Wiley India. 